\title{
Using Honorific Names of Indonesian-Japanese Business E-mails
}

\author{
The Comparison of Indonesian and Japanese E-Mail
}

\author{
Miftachul Amri \\ Universitas Negeri Surabaya \\ Surabaya, Indonesia \\ miftachulamri@unesa.ac.id
}

\begin{abstract}
The ability of Japanese language graduates to write Japanese and Indonesian emails is a necessity. The indication is that many graduates are not able to adapt to the real world of work, especially on email writing. The purpose of this study is to describe the "honorific name" in business e-mails in Indonesian and Japanese. This study used qualitative method with each using 300 emails Japanese and Indonesian. The result of this study reveals that the writing ability of honorific name both email Japanese and Indonesian were low. Honorific name seen in the "title" of Indonesian e-mail was divided into 9 categories and 7 categories in Japanese e-mail. The characteristic of changing greeting expressions by the partner was visible to the Indonesian e-mails. Even for close-minded people, they use "Mas (name)". Such a phenomenon could not be seen in Japanese e-mails. Thus, Japanese language learners need to understand the procedure of writing emails, both in Indonesian and Japanese.
\end{abstract}

Keywords-honorific, Japanese e-mails, Indonesian e-mails,

\section{INTRODUCTION}

The main point of this study is honorific use between Indonesian and Japanese e-mails. It is natural to express to the superior person with "honorific title"、By the relationship with the opponent, "title" is also used. For example, in junior colleagues in everyday life, "(name) san, how are you?" Although it may be enough with the expression "、As for seniors and bosses, using the title "(Name)", "(Name) san, how are you?" "Does (name) like you are doing fine?" Also, for example, using the "title" such as "(Name)" is exchanged via email, when using " san" of the honorific name, it will be hard to use for those who are not familiar.

In business documents, it is written as "(name) dono". The "honorific name" of e-mails and letters has customs to polite more than "honorific names" of conversation. "Honorifics" such as "Mr. President" and "Department Manager" are also used, but they will be rarely used in daily conversation. By the relationships and the scenes with the other party "honorific" it is also used.

\section{A. Previous Study}

Murakami Hideki [1] describes "address". Murakami explains below. "In business e-mails, be sure to write your address on the first line. Thus, it is to confirm who the mail is addressed to, first, company name, department name, name (full name) and then write "sama", it says.

When sending it to a person outside the company, the address is too omitting by name alone. The company name should also be included if possible. Also, in spite of the company, name of the person wrote in the full name, to give a "sama" is the basic. If "hiragana" "sama" is a very close relationship, you can use it.

But, because it is a crushed expression there is a possibility that seems to be "over familiar"to the opponent.

About the method of "address", he stated as follows. Unify address as "sama" Recently "dono" is not used so much, there is a tendency to be "sama".

When you do not know the person in charge Make it understood to which department and person in charge such as "Mr. . . General Affairs Department, Inc." ". . Person in charge of reporting company" etc

When putting "teacher" in address "Teacher" is not treated as title, so you can use "Professor Taro Yagi" instead of "sama".

When sending by many participants Use "everyone" "everybody" etc. It is pointed out that "everyone else" is a mistake. That is Murakami's explanation.

According to Shibuya Tadayoshi [2], The wording is also influenced by the intimacy of the speaker and the listener. For people who are generally not familiar, people who are far away from psychology are given polite language. So, criminal expression can be avoided for first-time people and others. But, being spoken to an interviewee who is using crushed expressions, it feels as pushed away. He says. Also, "It is about people's way of calling out that the relationship between affinities is visible". 
The thinner the degree of intimacy, the more the usage of a honorific name changes. It seems reasonable to use " dono" if the affinity is far away.

In the Japanese Language Dictionary (2006), " Chan is used in conjunction with a person's name or a noun representing a person (a change in suffix" $\sim$ san "). It is usedwhen calling a person with a close relationship, especially when calling with close friends. "It is explained.

Toshika Oshima [3] explains the usage of "title" as follows. It is used at the beginning of the mail, the company name and name of the opponent. In this case, it is important to add a "title" to it. It depends on the degree of friendship with the partner and whether the partner is one or more, or whether it is an individual, a company, or an organization.

\section{B. Students' Interest and The Important of Business Correspondence in Working World}

On the results of the survey on the importance of business Japanese language education and the interests of learners in business Japanese, Amri [4] reports. "There are over 300 people enrolled in the Department of Japanese Studies at the State University of Surabaya (Unesa) not everyone will become a Japanese teacher, but there are few people who wish to work for a Japanese company. We conducted a questionnaire survey on interests in Business Japanese for Unesa Japanese learners. "Said. Of the 154 people, when asked why studying Japanese, Among the reasons most, "I would like to be a Japanese teacher" (53 people), Next, "I would like to work for a Japanese company" (46), "The way to write Japanese business writing" (109 people) resulted.

Kondo Aya [5] says, in recent years, opportunities to use Japanese rather than English are increasing in companies entering from Japan in Asia, including China, Korea and Indonesia. Besides, there seems to be an increasing number of cases of using Japanese when transferring Japanese technology to developing countries (Indonesia).

\section{METHOD}

This paper is comparing the use of honorific names of Indonesian and Japanese E-Mail. For the object of this research are 300 e-mails written in Indonesian written by Indonesians and 300 e-mails written in Japanese written by Japanese, total 600 e-mails. But, of the 300 Indonesian e-mails, four e-mails (e-mail 71, 72, 73, 266) were sent by Indonesian people to Japanese people in Indonesian languages, and one (mail 300) was sent by Japanese people to Indonesian people in Indonesian language.

\section{RESUlTS AND DISCUSSION}

\section{A. Variations of "Honorifics" use in Japanese -Indonesian mail addres}

Before entering the result of the usage status of "title", first look at the usage status of "address". There are 204 mails with "address". In Indonesian language, there are 207 names. But, in
Indonesian, there were 10 e-mails without "honorific names" in "address", that are, e-mails used for "abandonment" were seen. In the case of Japanese, one form of "abandonment" could not be seen.

Omit, out of 300, "mailing address" with Japanese mail is 204 , usage rate is $68 \%$. In the case of Indonesian e-mail, "address" was found in 207 mails, and a usage rate of $69 \%$ was seen.

In the above results, there were 96 Japanese e-mails without "address", usage rate is $32 \%$. Unlike the result of "address" in Indonesian mail, Here, there was no form of "Non-Honorific" mail in "address". In other words, it is considered that in Japanese mails, it is thought that it is impossible to "abandon" (in English: addressing by last name only) exchanging business e-mails for subordinates / close relationships.

\section{B. Variation of "Honorifics" use of Japanese e-mail}

"Honorifics" seen in Japanese e-mail were divided into 7 variations. They are " san / Mr. " and " sama" of " Dono" " sama" " san" " everyone" " president". The use of the "honorific name", which was the most many, has " dono" (106).

Only "one title" "honorific name" of "sama." was seen. So, Mr. Hide Murakami[1], says that, in "Address" "Dono" is not used much recently and tends to be unified to "sama", but as can be seen from the above results, The largest number of emails using "Dono" was.

In this case, $\langle\mathrm{H} \mathrm{S}\rangle$ is sending an e-mail to $\langle\mathrm{K}\rangle$ and the local staff $\langle\mathrm{I}\rangle$ at the same time. These e-mails are written in English and Japanese so that the recipient can understand the contents of the mail. In the case of English, he wrote Japanese ( san) for "Romaji", but after writing in English, he wrote ( san) when writing in Japanese.

In the above-mentioned e-mail, it is the exchange of e-mail between the same Japanese. (Mr. ) is used, and in Japanese in "main sentence" (with please) is written. From the viewpoint of human relations, it is considered that the receiver and the sender are close relationships.

\section{Usage status of "address" in Indonesian e-mail}

In Indonesian mail, there are 207 mails using "address", and 93 mails not using "address". Among them, there are 9 variations of "title", but in detail the following.

As mentioned above, it is clear that Japanese mail has a higher usage rate of "address" than Indonesian mail. The reason that there is no "address" in the Indonesian e-mail seems to be because it is the case where it interacts with the reply mail or the same recipient. In this part, I will to show how to use variations of various "honorific" was seen.

\section{Variation of "Title" use of Indonesian e-mail}

In the above, there are 197 mails with "title". Now, to understand the above expression of "title" in Indonesian language, I would like to first explain as follows. Bapak is a "honorific title" or a call for men against elderly people or high social positions. $\mathrm{Ibu}$ is a "honorific title" or a call for women 
against elderly people or high social positions. Looking at these two words from the criteria of "married or unmarried", "Bapak" is used for married men and "Ibu" for married women. If you do not know about married / unmarried, add age judgment there. In other words, use 'Bapak' or 'Ibu' for people over the age of 30 . If friendliness adds to human relations, "Bapak" and "Ibu" will be "Pak" and "Bu".

\section{E. Pattern of 'disposition' of Indonesian e-mail}

Even in the business scene, in Indonesian e-mails, there was also a mail of abandonment without "honorific title". Especially, it is mail from the boss to his subordinates. There are ten mails of "abandonment" that have no "honorific name" among 207 messages with "address". In other words, "recipient" title is not written in "address", but there are e-mails that only a list of names of recipients and "honorific words" and names.

The following one pattern can be seen on ten "abandonment". In the above, we write only the name "R" in "address". Sender is R's boss, it is an example of "no title" and exchange of business e-mail. Regardless of internal mail, write the sender's name and company name in the signature as well. "Trims" of the end of sentence is an abbreviation of "Terima kasih (thank you)" in the beginning. It is considered difficult to use unless it is an intimate relationship.

\section{CONCLUSION}

Comparison of the use situation of "honorific title" in "address" of Japanese and Indonesian mail and usage variation of "honorific title" in "address" and "body" is summarized as follows.

The differences of usage of "title" in Japanese / Indonesian language are summarized in the following three points. First, the use of "honorific title" is more Indonesian than Japanese. Second, The characteristic of changing the "honorific title"expression by the other person is visible to the Indonesian e-mail. Third, In the use of "honorific title", it is clear that the upper-lower relationship is clearer in Japanese than in Indonesian. In the case of Japanese, the hierarchical relationship reflects and even if we are friendly, you treat the partner, so you cannot write " chan" by e-mail. Also, if we are a member of a intimate group, you may use " san" with "honorific name" of "address". To respect recipients, even if you exchange e-mails, there is a general tendency to be fixed to " sama". In some cases, how to use the "honorific" is lost to work colleagues. The "title" of "address" uses " dono / $\sim$ sama", but in the "body" uses " san" in some cases. Yet, in the reverse pattern, "address" was " san", in the "body" there was none of " dono / sama". In this research, the writing ability of honorific name both email Japanese and Indonesian was low. And To Improve writing ability, Japanese language learners need to understand the procedure of writing emails, both Indonesian and Japanese.

\section{REFERENCES}

[1] Murakami and Hideki, Bijinesu Me-ru IikaeJiten. Nihonjitsugyou Shuppansha, 2012.

[2] Shibuya and Tadayoshi, Riron to Bunseki. 1982.

[3] Oshima and Toshika, Bijinesu Me-ru Bunrei \& Fure-zu Jiten. 2006.

[4] M. Amri, "Amri, Miftachul "Bijinesu Nihongo No Me-ru No Zenbun Wa (Aisatsu) No Ten De DonoYouna Tokuchou Ga Aruka," Nihongo Indones. Nihongo Kyouiku Gakkai, vol. 5, no. 2, pp. 71-82, 2013.

[5] Kondo and Aya, Bijinesu Ni Okeru Ibunkakan KomyunikeeshonNihongo Deno Kaigi Wa Hikouuritsu. 2005. 